\title{
High frequency of class 3 allele in the human insulin gene in Japanese Type 2 (non-insulin-dependent) diabetic patients with a family history of diabetes
}

\author{
M. Nomura, N. Iwama, M. Mukai, Y.Saito, R. Kawamori, M. Shichiri and T. Kamada \\ First Department of Medicine, Osaka University Medical School, Osaka, Japan
}

\begin{abstract}
Summary. The restriction fragment length polymorphism in the $5^{\prime}$ flanking region of the human insulin gene was studied in 155 nonobese Japanese subjects. The subjects consisted of 36 Type 2 (non-insulin-dependent) diabetic patients with a family history of diabetes mellitus, 42 Type 2 diabetic patients without a family history of diabetes, 42 Type 1 (insulin-dependent) diabetic patients, and 35 healthy volunteers who served as control subjects. It was demonstrated that, in Japanese healthy subjects and diabetic patients, the incidence of the insertion into $5^{\prime}$ flanking region of the insulin gene was found to be significantly lower $(p<0.05)$ than those in Caucasians and other races already investigated. Even though the class 3 gene
\end{abstract}

allelic frequency in Type 2 diabetic patients without a family history of diabetes $(0.060)$ was not higher than that in healthy subjects $(0.014)$, in nonobese Type 2 diabetic patients with a family history of diabetes the allelic frequency of the inserted class 3 gene (0.111) was found to be significantly higher $(p<$ 0.02 ) than that in control subjects. These data suggest that the insulin gene polymorphism relates to the aetiology of diabetes mellitus.

Key words: Restriction fragment length polymorphism, insulin gene, Japanese Type 2 diabetes mellitus
The length polymorphism of the restriction fragments of the human insulin gene has been discovered [1], and its association with Type 2 (non-insulin-dependent) diabetes mellitus has been studied [2-4]. A polymorphic region of heterogeneous length occurs about 350 base pairs (bp) at the $5^{\prime}$ coding portion of human insulin gene. Those length polymorphisms are due to insertions of varying sizes. Bell et al. [4] categorized these lengths into class 1 alleles of $\sim 570 \mathrm{bp}$, class 2 alleles of $\sim 1320 \mathrm{bp}$, and class 3 of $\sim 2470 \mathrm{bp}$ in size.

It has been demonstrated that the large insertion of these sequences is more frequently found in both healthy subjects and Type 2 diabetic patients of Caucasians [2-4], American blacks [4, 5] and Pima Indians [6] than of Japanese [7, 8]. However, there still remains controversy on the association of the insertion with diabetes mellitus.

In this study the analysis of restriction length polymorphism of the insulin gene regions was performed in Japanese healthy volunteers, nonobese Type 2 diabetic patients with or without family history of diabetes and Type 1 (insulin-dependent) diabetic patients.

\section{Subjects and methods}

\section{Subjects}

In 155 unrelated, nonobese Japanese, restriction fragment length polymorphisms (RFLP) presented in the $5^{\prime}$ flanking region of the insulin gene were investigated. In order to clarify the relationship be- tween RFLP and diabetes mellitus, those subjects were divided into 4 groups as follows: group 1, nonobese Type 2 diabetic patients with a family history of diabetes at least within two generations $(n=36)$; group 2 , nonobese Type 2 diabetic patients without a family history of diabetes $(n=42)$; group 3, Type 1 diabetic patients $(n=42)$; group 4 , nonobese healthy volunteers which served as control subjects $(n=35)$. The mean ages were matched among groups $1(57+13$ years, mean $+S D), 2(61 \pm 11$ years) and 4 ( $56 \pm 10$ years). There were no significant differences between group 1 and group 2 in clinical features including obesity indices, fasting plasma glucose concentrations and $\mathrm{HbAlc}$ levels. There were also no significant differences in mean onset age of diabetes mellitus (group 1: $45 \pm 11$; group 2: $47 \pm 11$ years), and in mean duration of the disease (group 1: $12 \pm 8$; group 2: $14 \pm$ 8 years) between the two groups. However, the mean age of group 3 was considerably younger ( $10 \pm 14$ years) than other groups, because 26 juvenile Type 1 diabetic patients (mean age $9 \pm 3$ years) were included in this group.

Obese subjects were not included in this study. The diabetic patients examined in this study were all nonobese and hypoinsulinaemic.

\section{Methods}

Ten mililitres of heparinized whole blood samples were centrifuged and precipitates were suspended with equal volumes of distilled water. After centrifuging, precipitates were treated with proteinase and RNase A (Sigma Chemical Co., St Louis, Mo, USA). DNA was extracted by phenol, then dialized with $0.1 \mathrm{~mol} / \mathrm{I} \mathrm{TE}(\mathrm{pH} 7.4)$. Ten micrograms of DNA was digested by $50 \mathrm{U}$ of endonuclease Bgl-I (Bethesda Research Laboratories, Gaithersburg, Md, USA) and Sac-I (Takara Shuzo Co., Kyoto, Japan), respectively, at $37^{\circ} \mathrm{C}$ for $14 \mathrm{~h}$ under the conditions suggested by the manufacturers. After gel-electrophoresis, southern transfer to the nitrocellulose filter (Schleicher \& Schuell, Dassel, GDR) was conducted. A hybridization was carried out at $65^{\circ} \mathrm{C}$ for $48 \mathrm{~h}$ with nicktranslated human insulin c-DNA (pgHI 6.2, provided by Dr. P. Rotwein, St Louis, Mo, USA) digested 
with both BgI-I and BgI-II (Takara Shuzo Co., Kyoto, Japan). After washing the filter, autoradiography was done at $-70^{\circ} \mathrm{C}$ for $3-4$ days with intensifying screen (E.I. Du Pont de Nemours \& Co., Wilmington, DE, USA).

Since no incomplete digestions had been demonstrated either by Bgl-I or by Sac-I, classification of RFLP of insulin gene was done according to the results with Bgl-I digestion [4].

\section{Statistical analysis}

Statistical analyses were carried out by chi-square analysis and the Student's t-test for unpaired data.

\section{Results}

As shown in Table 1, the allelic frequencies in control subjects (group 4) were 0.986 in class 1,0 in class 2 , and 0.014 in class 3 . The corresponding frequencies were $0.889,0,0.111$ in Type 2 diabetic patients with a family history of diabetes (group 1), and $0.940,0,0.060$ in Type 2 diabetic patients without a family history of diabetes (group 2) respectively. The frequencies in Type 1 diabetic patients were 0.976 in class $1,0.012$ in class 2 and 0.012 in class 3 . Even though the class 3 gene allelic frequency in group 2 was not higher than group 4 , that figure in group 1 was significantly higher than group 4 $(p<0.02)$ by chi-square analysis. When groups 1 and 2 were combined as a Type 2 diabetes mellitus group, the allelic frequency of class $3(0.084)$ was significantly different from that in control subjects (group 4) $(p<0.05)$. There was no significant difference between groups 3 and 4 in this respect.

As far as genotypic analysis is concerned, class $1 / 3$ heterozygote was revealed to be $22 \%(n=36)$ in group 1 , $12 \%(n=42)$ in group 2, 2.4\% $(n=42)$ in group 3 and $2.8 \%(n=35)$ in group 4 respectively. There were significant differences between groups 1 and $3(p<0.02)$ and also between groups 1 and $4(p<0.01)$. However, there were no statistical differences between group 2 and groups 3 or 4 respectively.

Only one class 2 gene allele was found in one Type 1 diabetic patient, whose genotype was class $1 / 2$ heterozygote.

\section{Discussion}

In healthy subjects, the reported allelic frequencies of class 3 gene inserted in the $5^{\prime}$ end of the insulin gene were as follows: $0.182-0.319$ for Caucasians [2, 3, 4], 0.214-0.292 for American blacks [3-5], and 0.237 for Pima Indians [6]. With the present study it was found that, in nonobese Japanese healthy subjects over 40 years of age, the insertion frequency of the class 3 gene was only 0.014 . This figure corroborates two recently published papers concerning Japanese (0.024 [7] and 0.043 [8] respectively), and is found to be significantly lower as compared with those in Caucasians [2-4], American
Table 1. Allelic and genotypic frequencies of the polymorphic loci

\begin{tabular}{llllllllll}
\hline & \multicolumn{3}{c}{ Genotypes } & & & \multicolumn{3}{c}{ Allelic frequencies } \\
\cline { 2 - 3 } \cline { 7 - 9 } & $\mathrm{n}=$ & $1 / 1$ & $1 / 2$ & $1 / 3$ & & 1 & 2 & 3 \\
\hline Group 1 & 36 & 28 & 0 & 8 & & 0.889 & 0 & 0.111 \\
Group 2 & 42 & 37 & 0 & 5 & & 0.940 & 0 & 0.060 \\
Group 3 & 42 & 40 & 1 & 1 & & 0.976 & 0.012 & 0.012 \\
Group 4 & 35 & 34 & 0 & 1 & & 0.986 & 0 & 0.014 \\
\hline
\end{tabular}

Group 1, nonobese Type 2 diabetic patients with a family history of diabetes mellitus; group 2, nonobese Type 2 diabetic patients without a family history of diabetes; group 3, Type 1 diabetic patients; group 4 , healthy volunteers (control subjects)

blacks $[4,5]$ and other races $[4,6]$. Since in some of these studies $[3,4,6]$ obese subjects were included, this comparison may not be appropriate. With respect to class 2 gene, allelic frequencies were reported to be higher in American blacks [4], but the allelic frequency was found to be as low in Japanese subjects as in Caucasians [4]. These findings clearly suggest the presence of the racial differences in the allelic frequencies of RFLP in the insulin gene.

In the present study the significantly higher insertion rate of class 3 gene in the $5^{\prime}$ end of insulin gene in Japanese nonobese Type 2 diabetic patients with a family history of diabetes mellitus (odd ratio 6.86) was demonstrated. Even total Type 2 diabetic patients examined with and without a family history exhibited the significantly higher frequency in insertion than control subjects. The reported incidences of class 3 gene insertion in Japanese Type 2 diabetic patients were 0.038 $(n=102)$ [7] and $0.038(n=104)$ [8] respectively. These two figures were not statistically different from our result in total Type 2 diabetes mellitus by chi-square analysis. Since the frequency of insertion in control subjects in our study was very low $(0.014)$, there was a significant difference in incidence of insertion between control subjects and Type 2 diabetic patients. Thirty-six patients out of 78 Type 2 diabetic patients $(46 \%)$ in the present study and 18 out of $52(35 \%)$ in the cases studied by Haneda et al. [8] had a positive family history of diabetes mellitus, whereas no respective data were provided in the study by Awata et al. [7]. These differences may have contributed to the discrepant findings.

Thus, our findings may put weight on the importance of class 3 gene insertion in relation to diabetes mellitus. However, a mass study using a large number of patients should be required to draw the final conclusion.

A pedigree analysis of the size of DNA inserts in the diabetic families is now under investigation to clarify the linkage between the presence of the polymorphic insert and diabetes mellitus.

Recently Owerbach et al. [9] have reported the association of macroangiopathy, arteriosclerosis, and hypertriglycaemia with class 3 gene. In this study, the occurrence of macroangiopathy indicated by the abnormal ECG were $46 \%(6 / 13)$ of Type 2 diabetic patients with 
class 3 and $28 \%(18 / 65)$ of Type 2 diabetic patients without class 3 gene insertion respectively. Although the occurrence of macroangiopathy seemed to be higher in Type 2 diabetic patients with class 3 gene, there was no significant difference between two groups. There were no significant differences in lipid levels between the group with or without class 3 gene.

Bell et al. [4] and Hitmann et al. [10] have reported the association of class 1 gene to Type 1 diabetic patients, but any specific association between class 1 and Type 1 diabetic patients was not confirmed in this study.

In conclusion, in Japanese healthy subjects and diabetic patients, the incidence of the insertion into $5^{\prime}$ flanking region of the insulin gene was found to be significantly lower than those in Caucasians and other races already investigated. However, in Japanese nonobese Type 2 diabetic patients, the frequency of the inserted class 3 gene was found to be significantly higher than those in healthy subjects. This resulted from the higher frequency of class 3 gene seen in nonobese Type 2 diabetic patients with a family history of diabetes.

Since the role which the polymorphic locus might play in the aetiology of diabetes is still controversial, and there is still little evidence whether the insertion in the $5^{\prime}$ flanking region affects insulin gene expression, further investigation of pedigrees in families with strong associations with diabetes mellitus or combined analyses with other polymorphisms appears warranted.

Acknowledgement. We wish to thank P. S. Rotwein, M. D., Washington University School of Medicine, St.Louis, Mo, USA, for providing plasmid (pgHI. 6.2). We are indebted to Professor K. Matsubara, Institute for Molecular and Cellular Biology, Osaka University, Japan, for valuable discussions during this project. This work was supported in part by the Grant-in-aid for scientific research (no. 60480269) from the Ministry of Education, Japan.

\section{References}

1. Bell GI, Karam JH, Rutter WJ (1983) Polymorphic DNA region adjacent to the $5^{\prime}$ end of the human insulin gene. Proc Natl Acad Sci USA 78: 5759-63

2. Owerbach D, Nerup J (1982) Restriction fragment length polymorphism of the insulin gene in diabetes mellitus. Diabetes 31 : 275-277

3. Rotwein PS, Chirwin J, Province M, Knowler WC, Pettitt DJ, Cordell B, Goddman HM, Permutt MA (1983) Polymorphism in the 5 flanking region of the insulin gene: a genetic marker for non-insulin dependent diabetes. $\mathrm{N}$ Engl J Med 308: 65-71

4. Bell GI, Horita S, Karam JH (1984) A polymorphic locus near the human insulin gene is associated with insulin-dependent diabetes mellitus. Diabetes 33: 176-183

5. Elbein S, Rotwein P, Permutt MA, Bell GI, Sanz N, Karam JH (1985) Lack of association of the polymorphic locus in the $5^{\prime}$-flanking region of the human insulin gene and diabetes in American blacks. Diabetes 34: 433-439

6. Knowler WC, Pettitt DJ, Uasquez B, Rotwein PS, Andreone TL, Permutt MA (1983) Polymorphism in the $5^{\prime}$ flanking region of the human insulin gene. Relationships with noninsulin-dependent diabetes mellitus, glucose and insulin concentrations, and diabetes treatment in the Pima Indians. J Clin Invest 74: 2129-2135

7. Awata T, Shibasaki Y, Hirai H, Okabe T, Kanazawa Y, Takaku F (1986) Restriction fragment length polymorphism of the insulin gene region in Japanese diabetic and non-diabetic subjects. Diabetologia 28: 911-913

8. Haneda H, Kobayashi M, Maegawa H, Shigeta Y (1986) Low frequency of the large insertion in the human insulin gene in Japanese. Diabetes 35: 115-119

9. Owerbach D, Johansen K, Billesbolle P, Poulsen S, Schroll M, Nerup J (1982) A possible association between DNA sequences flanking the insulin gene and atherosclerosis. Lancet 2: 1291-1293

10. Hitmann GA, Tarn AC, Winter RM, Drummond V, Williams LG, Jowett NI, Bottazo GF, Galton DJ (1985) Type I (insulin-dependent) diabetes and a highly variable locus close to the insulin gene on chromosone 11. Diabetologia $28: 218-222$

Received: 21 February 1986

and in revised form: 10 April 1986

Dr. Makoto Nomura

First Department of Medicine

Osaka University Medical School

1-1-50, Fukushima, Fukushima-Ku

Osaka 553, Japan 